Anuario del Instituto de Historia Argentina, vol. 17, nº 1, e045, junio 2017.

ISSN 2314-257X

Universidad Nacional de La Plata.

Facultad de Humanidades y Ciencias de la Educación.

Centro de Historia Argentina y Americana

\title{
Oberti, Alejandra, Las revolucionarias. Militancia, vida cotidiana y afectividad en los setenta, Buenos Aires, Edhasa, 2015, 280 ppp
}

\author{
Andrés Torres * \\ * Universidad Nacional de General Sarmiento, Argentina | andd.torres@gmail.com
}

Las revolucionarias. Militancia, vida cotidiana y afectividad en los setenta comprende la investigación llevada a cabo por Alejandra Oberti sobre las construcciones identitarias y de subjetividades de aquellas mujeres que conformaron los grupos de izquierda revolucionaria en la República Argentina durante la década de 1970. Enfocándose particularmente en las trayectorias políticas de Montoneros y el PRT-ERP, la autora intenta comprender las formas de participación política de estas mujeres, su finalidad dentro de los grupos guerrilleros y sus testimonios una vez terminada la experiencia revolucionaria.

Oberti, socióloga y especialista en estudios de género y del pasado reciente argentino produce en este libro un aporte que se inserta al corpus dedicado a analizar las trayectorias políticas de los grupos de la denominada "nueva izquierda" argentina prestando especial atención a la militancia femenina (Andrea Andújar, 2009; Karin Grammático, 2011, entre otrxs), y como explica la autora, desde la óptica del género y no sobre éste. A través del análisis de documentos partidarios destinados a la conformación y organización de unidades militantes, Oberti se encargara entonces de examinar tanto las formas que Montoneros y el PRTERP tenían de concebir y representar a la militancia femenina, así como de aquellas actividades o actitudes que se esperaban o reservaban exclusivamente a las integrantes femeninas en los mismos. A través del libro será posible vislumbrar las diferencias entre lo que las agrupaciones de la militancia revolucionaria concebían que era el rol de la mujer en la nueva sociedad y aquellas tareas reservadas exclusivamente a las mismas para el triunfo de la revolución y los anhelos que estas demuestran de formar parte más activa del intento de toma del poder. Para llevar a cabo esta tarea, la autora se valdrá de conceptos como el de perfomatividad del género elaboradas por teóricas de género o queer como Judith Butler para explicar al género "no como acto individual y voluntario de un individuo sino como una serie de prácticas ritualizadas y reiteradas en el tiempo por medio de las cuales el discurso produce los fenómenos que nombra” (Oberti, 
2015, pág .26). También utiliza el análisis de Héctor Schmucler sobre el uso de testimonios de participantes de organizaciones guerrilleras para conocer sus construcciones del periodo revolucionario. A ello le suma los estudios de Nelly Richard y Sylvia Molloy sobre tecnologías de género para conocer qué concepciones estas mujeres tenían sobre la relación entre la política y su vida cotidiana, la relación con sus padres, la violencia, la sexualidad y la maternidad, etc.

El libro se encuentra organizado en tres apartados que conforman en su totalidad cinco capítulos y un epílogo a modo de conclusión. La disposición de dichos apartados permite al lector seguir una estructura analítica en la que Alejandra Oberti sitúa en primer lugar la construcción de subjetividades y responsabilidades según el género que los cuadros creían necesarias para la revolución. A continuación, los dos siguientes capítulos contenidos en el segundo apartado del libro se centran en la participación política que las mujeres del PRTERP y Montoneros tuvieron en el transcurso de los años de actividad de ambas organizaciones. Luego, Oberti se dedica a analizar en profundidad en el último apartado las memorias de aquellas mujeres que participaron del intento revolucionario. Con estos registros orales intentará reconstruir las visiones que éstas tenían sobre temas tales como la afectividad, el tiempo de la revolución, el uso de la violencia y su participación en tareas de inteligencia o robos para abastecerse de armas, entre otros. En lo que concierne a los testimonios utilizados en este apartado, la autora, valiéndose de estudios como los de Cosse (2010) destaca primordialmente el doble quiebre de representaciones a las que se enfrentaron las revolucionarias de la época de 1970, quienes no solo se descubrían viviendo un periodo signado por cambios en la política nacional sino que además intentaban cambiar las formas de "ser mujeres". Por lo tanto, su participación dentro de las organizaciones armadas, que comprendía fundamentalmente la función de cuidadoras del hogar militante y de los futuros revolucionarios entraba en dicotomía con un contexto más amplio de liberación de la sexualidad femenina y de participación de estos sujetos en nuevos ámbitos. Por último, en el epílogo la autora genera una conclusión sobre las construcciones identitarias femeninas en el periodo situado por la misma entre la segunda mitad de la década de 1960 hasta el golpe de Estado del Proceso de Reorganización Nacional de 1976 en un contexto más general de cambios sobre la percepción que se tenía sobre las mujeres en la sociedad argentina en su totalidad.

El estudio de la propaganda guerrillera, como Moral y proletarización de 1972 para los cuadros del PRT-ERP o Montoneros. Línea político-militar para el caso de las organizaciones armadas peronistas y con el análisis de los testimonios de las mujeres que formaron parte de dichas organizaciones permiten al lector conocer las conclusiones a las que ambas agrupaciones llegaban. Entre sus líneas se pueden encontrar análisis sobre el panorama nacional e internacional, o que se esperaba de aquellos sujetos que simpatizaban o conformaban la izquierda revolucionaria. Aquí se evidencian las diferencias entre los casos estudiados, hallándose planteos sobre la necesidad de abandonar la moral e ideología burguesa para abrazar la conciencia revolucionaria en el caso del PRT-ERP o el llamado a generar "frentes de masas" que convoquen a estudiantes, trabajadores y sindicalistas por parte de Montoneros. Pero la autora sostendrá que aunque los documentos analizados llamen a una acción conjunta de hombres y mujeres comprometidos con la causa revolucionaria, se destacan las diferencias discursivas basadas entre quienes comprenden los sujetos ideales del "hombre nuevo" revolucionario y aquellas que deberán conformarse con realizar tareas secundarias o de apoyo menor como la acogida de algún compañero que entra a la lucha clandestina.

Oberti plantea que al no poder lograr identificarse las entrevistadas como guerrilleras ni tampoco como simples mujeres, esposas o madres, optó por analizarlas como mujeres/militantes/madres al reconocer diferencias entre el espacio de la política signado por la violencia y aquel de la vida cotidiana marcado por el deber ser mujer. Por lo tanto, el planteo inicial de la autora sobre la conformación identitaria femenina revolucionaria se encuentra afectado por la necesidad de no abandonar en su estudio ninguno de los roles impuestos a las mujeres en esa época. Ello es explicitado a través del uso de fuentes orales que permitirán al 
lector comprender qué visiones tenían estas mujeres de la violencia política, su participación real dentro de las organizaciones y si la supuesta paridad planteada en los documentos de formación se cumplía efectivamente.

La propuesta de este libro por lo tanto resulta de importancia para todos aquellos que se encuentren interesados por temas del pasado reciente argentino, quienes deseen incorporar conocimientos sobre la participación militante de las mujeres en los grupos de izquierda revolucionaria así como también sobre las posibilidades de uso de los registros orales en la reconstrucción histórica. 